\title{
EGU21-9586
}

https://doi.org/10.5194/egusphere-egu21-9586

EGU General Assembly 2021

(c) Author(s) 2021. This work is distributed under

the Creative Commons Attribution 4.0 License.

\section{X-rays observations at the Säntis Tower: Preliminary results}

\author{
Antonio Sunjerga ${ }^{1}$, Pasan Hettiarachchi ${ }^{2}$, David Smith ${ }^{3}$, Marcos Rubinstein ${ }^{4}$, Vernon Cooray ${ }^{2}$, \\ Mohammad Azadifar ${ }^{1}$, Amirhossein Mostajabi ${ }^{1}$, and Farhad Rachidi ${ }^{1}$ \\ ${ }^{1}$ EPFL, Lausanne, Switzerland (antonio.sunjerga@epfl.ch) \\ ${ }^{2}$ Uppsala University, Uppsala, Sweden \\ ${ }^{3}$ UC Santa Cruz - Physics Department \\ ${ }^{4}$ University of Applied Sciences and Arts of Western Switzerland in Yverdon-les-Bains, Switzerland
}

X-ray production has been unambiguously observed in case of natural downward lightning and artificial rocket-and-wire lightning (e.g., [1],[2]). In the case of natural upward lightning, strong x-ray bursts have been observed from one event initiated from a wind turbine in Japan [3]. Low-energy $x-$ rays have also been observed from upward flashes at the Gaisberg Tower in Austria [4].

We present data associated with five negative upward flashes occurred at the Säntis Tower in Switzerland in 2020. The data consist of simultaneous measurements of $x$-rays from two different sensors, lightning current measurements at the tower and nearby electric field observations. X-ray emissions were observed prior to some of the return strokes in two out of the five flashes.

The observed X-rays, which were observed just prior to the return stroke phase, are characterized by initial bursts of some hundreds of keV, followed by a rapid increase to values exceeding $1 \mathrm{MeV}$, less than a microsecond before the initiation of the return stroke.

All of the observed X-ray events occurred for return strokes with relatively large peak currents (greater than $8 \mathrm{kA}$ ), which were preceded by high electric field changes. For that reason, our electric field sensor was saturated in most cases at about 5 microseconds prior to the initiation of the return stroke. The dynamic range of the electric field sensor has now been modified to avoid saturation, allowing to better identify the origin of the x-ray emissions in our future events.

For two out of the five analyzed upward negative flashes, we have also observed x-rays during the development of the dart leader phase. These observations are characterized by bursts with energy levels of several tens to hundreds of keV during the earlier phase of the dart leader process and exceeding $1 \mathrm{MeV}$ during the late phase.

[1] Moore, C. B., Eack, K. B., Aulich, G. D., \& Rison, W. (2001). Energetic radiation associated with lightning stepped-leaders. Geophysical Research Letters, 28(11), 2141-2144. https://doi.org/10.1029/2001gl013140

[2] Dwyer, J. R. (2003). Energetic Radiation Produced During Rocket-Triggered Lightning. Science, 
299(5607), 694-697. https://doi.org/10.1126/science.1078940

[3] Bowers, G. S., Smith, D. M., MartinezםMcKinney, G. F., Kamogawa, M., Cummer, S. A., Dwyer, J. R., Wang, D., Stock, M., \& Kawasaki, Z. (2017). Gamma Ray Signatures of Neutrons From a Terrestrial Gamma Ray Flash. Geophysical Research Letters, 44(19). https://doi.org/10.1002/2017gl075071

[4] Hettiarachchi, P., Cooray, V., Diendorfer, G., Pichler, H., Dwyer, J., \& Rahman, M. (2018). X-ray Observations at Gaisberg Tower. Atmosphere, 9(1), 20. https://doi.org/10.3390/atmos9010020 